\title{
The association of rocuronium dosing and first-attempt intubation success in adult emergency department patients
}

\author{
Nicholas M. Levin ${ }^{1}$ (1) $\cdot$ Megan L. Fix ${ }^{1}$ Michael D. April ${ }^{2}$ Allyson A. Arana ${ }^{3} \cdot$ Calvin A. Brown $\mathrm{III}^{4} \cdot$ on behalf of the \\ NEAR Investigators
}

Received: 23 November 2020 / Accepted: 23 March 2021 / Published online: 10 April 2021

(c) The Author(s), under exclusive licence to Canadian Association of Emergency Physicians (CAEP)/ Association Canadienne de Médecine d'Urgence (ACMU) 2021

\begin{abstract}
Background The recommended rocuronium dose for rapid sequence intubation is $1.0 \mathrm{mg} / \mathrm{kg}$; however, the optimal dose for emergency airway management is not clear. We assessed the relationship between rocuronium dose and first-attempt success among emergency department (ED) patients undergoing rapid sequence intubation.

Methods This is a secondary analysis of the National Emergency Airway Registry (NEAR), an observational 25-center registry of ED intubations. Ninety percent recording compliance was required from each site for data inclusion. We included all patients $>14$ years of age who received rocuronium for rapid sequence intubation from 1 Jan 2016 to 31 Dec 2018 . We compared first-attempt success between encounters using alternative rocuronium doses $(<1.0,1.0-1.1,1.2-1.3 \mathrm{and} \geq 1.4 \mathrm{mg} /$ $\mathrm{kg}$ ). We performed logistic regressions to control for predictors of difficult airways, indication, pre-intubation hemodynamics, operator, body habitus and device. We also performed subgroup analyses stratified by device (direct vs. video laryngoscopy). We calculated univariate descriptive statistics and odds ratios (OR) from multivariable logistic regressions with clusteradjusted 95\% confidence intervals (CI).

Results 19,071 encounters were recorded during the 3-year period. Of these, 8,034 utilized rocuronium for rapid sequence intubation. Overall, first attempt success was $88.4 \%$ for $<1.0 \mathrm{mg} / \mathrm{kg}, 88.1 \%$ for $1.0-1.1 \mathrm{mg} / \mathrm{kg}, 89.7 \%$ for $1.2-1.3 \mathrm{mg} / \mathrm{kg}$, and $92.2 \%$ for $\geq 1.4 \mathrm{mg} / \mathrm{kg}$. Logistic regression demonstrated that when direct laryngoscopy was used and when compared to the standard dosing range of $1.0-1.1 \mathrm{mg} / \mathrm{kg}$, the adjusted odds of a first attempt success was significantly higher in $\geq 1.4 \mathrm{mg} /$ $\mathrm{kg}$ group at 1.9 (95\% CI 1.3-2.7) relative to the other dosing ranges, OR 0.9 (95\% CI 0.7-1.2) for $<1.0 \mathrm{mg} / \mathrm{kg}$ and OR 1.2 (95\% CI 0.9-1.7) for the 1.2-1.3 mg/kg group. First-attempt success was similar across all rocuronium doses among patients utilizing video laryngoscopy. Patients who were hypotensive ( $\mathrm{SBP}<100 \mathrm{mmHg}$ ) prior to intubation had higher first-attempt success $94.9 \%$ versus $88.6 \%$ when higher doses of rocuronium were used. The rates of all peri-intubation adverse events and desaturation were similar between dosing groups, laryngoscope type utilized and varying pre-intubation hemodynamics.

Conclusions Rocuronium dosed $\geq 1.4 \mathrm{mg} / \mathrm{kg}$ was associated with higher first attempt success when using direct laryngoscopy and among patients with pre-intubation hypotension with no increase in adverse events. We recommend further prospective evaluation of the dosing of rocuronium prior to offering definitive clinical guidance.
\end{abstract}

Keywords Rapid sequence intubation · Emergency medicine · Critical care · Airway · Non-depolarizing paralytics · Depolarizing paralytics

Mediterranean Emergency Medicine Congress, 2019. Dubrovnik, Croatia. October 2019.

American College of Emergency Physicians, Research Forum. Denver, CO. October 2019.

Nicholas M. Levin

Nicholas.levin@hsc.utah.edu

Extended author information available on the last page of the article 


\section{Résumé}

Contexte La dose de rocuronium recommandée pour l'intubation à séquence rapide est de $1,0 \mathrm{mg} / \mathrm{kg}$, mais la dose optimale pour la prise en charge des voies respiratoires d'urgence n'est pas claire. Nous avons évalué la relation entre la dose de rocuronium et la réussite de la première tentative chez les patients des services d'urgence soumis à une intubation à séquence rapide. Méthodes Il s'agit d'une analyse secondaire du National Emergency Airway Registry (NEAR), un registre d'observation des intubations aux urgences dans 25 centres. Pour que les données soient prises en compte, chaque site devait respecter $90 \%$ des enregistrements. Nous avons inclus tous les patients âgés de plus de 14 ans qui ont reçu du rocuronium pour une intubation à séquence rapide du 1er janvier 2016 au 31 décembre 2018. Nous avons comparé le succès de la première tentative entre les rencontres utilisant des doses alternatives de rocuronium $(<1,0 \mathrm{mg} / \mathrm{kg}, 1,0-1,1 \mathrm{mg} / \mathrm{kg}, 1,2-1,3 \mathrm{mg} / \mathrm{kg}$ et $1,4 \mathrm{mg} / \mathrm{kg})$. Nous avons effectué des régressions logistiques pour contrôler les facteurs prédictifs des voies aériennes difficiles, l'indication, l'hémodynamique pré-intubation, l'opérateur, l'habitus corporel et le dispositif. Nous avons également effectué des analyses de sous-groupes stratifiées par dispositif (laryngoscopie directe contre vidéo-laryngoscopie). Nous avons calculé des statistiques descriptives univariées et des rapports des cotes (RC) à partir de régressions logistiques multivariables avec des intervalles de confiance (IC) à $95 \%$ ajustés par groupe Résultats 19071 consultations ont été enregistrées au cours de la période de trois ans. Parmi celles-ci, 8034 ont utilisé du rocuronium pour une intubation à séquence rapide. Dans l'ensemble, le succès de la première tentative était de $88,4 \%$ pour $<1,0 \mathrm{mg} / \mathrm{kg}, 88,1 \%$ pour 1,0 à $1,1 \mathrm{mg} / \mathrm{kg}, 89,7 \%$ pour 1,2 à $1,3 \mathrm{mg} / \mathrm{kg}$ et $92,2 \%$ pour $\geq 1,4 \mathrm{mg} / \mathrm{kg}$. La régression logistique a démontré que lorsque la laryngoscopie directe était utilisée et comparée à la gamme de dosage standard de 1,0-1,1 mg/ $\mathrm{kg}$, la probabilité ajustée de réussite de la première tentative était significativement plus élevée dans le groupe $\geq 1,4 \mathrm{mg}$ / $\mathrm{kg}$ à 1,9 (IC $95 \%$ 1,3-2,7) par rapport aux autres gammes de dosage, RC 0,9 (IC $95 \%$ 0,7-1,2) pour $<1,0 \mathrm{mg} / \mathrm{kg}$ et RC 1,2 (IC $95 \%$ 0,9-1,7) pour le groupe 1,2-1,3 mg/kg. La réussite de la première tentative était similaire pour toutes les doses de rocuronium chez les patients utilisant la vidéo-laryngoscopie. Les patients qui étaient hypotendus ( $\mathrm{SBP}<100 \mathrm{mmHg}$ ) avant l'intubation avaient un taux de réussite de la première tentative plus élevé $94,9 \%$ contre $88,6 \%$ lorsque des doses plus élevées de rocuronium étaient utilisées. Les taux de tous les effets indésirables péri-intubation et de désaturation étaient similaires entre les groupes de dosage, le type de laryngoscope utilisé et les différentes hémodynamiques pré-intubation

Conclusions Le rocuronium dosé à $\geq 1,4 \mathrm{mg} / \mathrm{kg}$ a été associé à une meilleure réussite de la première tentative lors de l'utilisation de la laryngoscopie directe et chez les patients présentant une hypotension avant intubation, sans augmentation des effets indésirables. Nous recommandons une évaluation prospective plus poussée du dosage du rocuronium avant de proposer une orientation clinique définitive

\section{Clinicians' capsule}

What is known about the topic?

The recommended dose of rocuronium for rapid sequence intubation is $1.0 \mathrm{mg} / \mathrm{kg}$ but evidence from emergency airway management is limited.

\section{What did this study ask?}

We assessed the association of rocuronium dosing on first-attempt success and adverse outcomes among emergency department patients.

\section{What did this study find?}

Rocuronium dosed $\geq 1.4 \mathrm{mg} / \mathrm{kg}$ was associated with higher first attempt success when using direct laryngoscopy and among patients with pre-intubation hypotension.

\section{Why does this matter to clinicians?}

The association between accurate weight-based rocuronium dosing and first-attempt success is important and may be further influenced by pre-intubation hypotension.

\section{Background}

Emergency intubation is a life-saving procedure commonly performed in the emergency department (ED) and rapid sequence intubation is the most prevalent method used. Rapid sequence intubation involves the near simultaneous administration of sedative and neuromuscular blocking agents to optimize the patient for a fast and safe endotracheal intubation. In the $\mathrm{ED}$, the two most common neuromuscular blocking agents are succinylcholine and rocuronium; however, recent utilization trends show rocuronium use is increasing over time[1].

Previous studies have reported no significant difference in first pass success or peri-intubation adverse events between these two medications [2-4]. However, the differential impact of varying weight-based dosing regimens was not analyzed. While early operating room studies have suggested that escalating doses of rocuronium result in better intubating conditions, the upper limit of rocuronium dosing was $1.0 \mathrm{mg} / \mathrm{kg}$ and therefore is hard to extrapolate to emergency department patients $[5,6]$. 
19071 intubations performed at sites with $>90 \%$ data capture

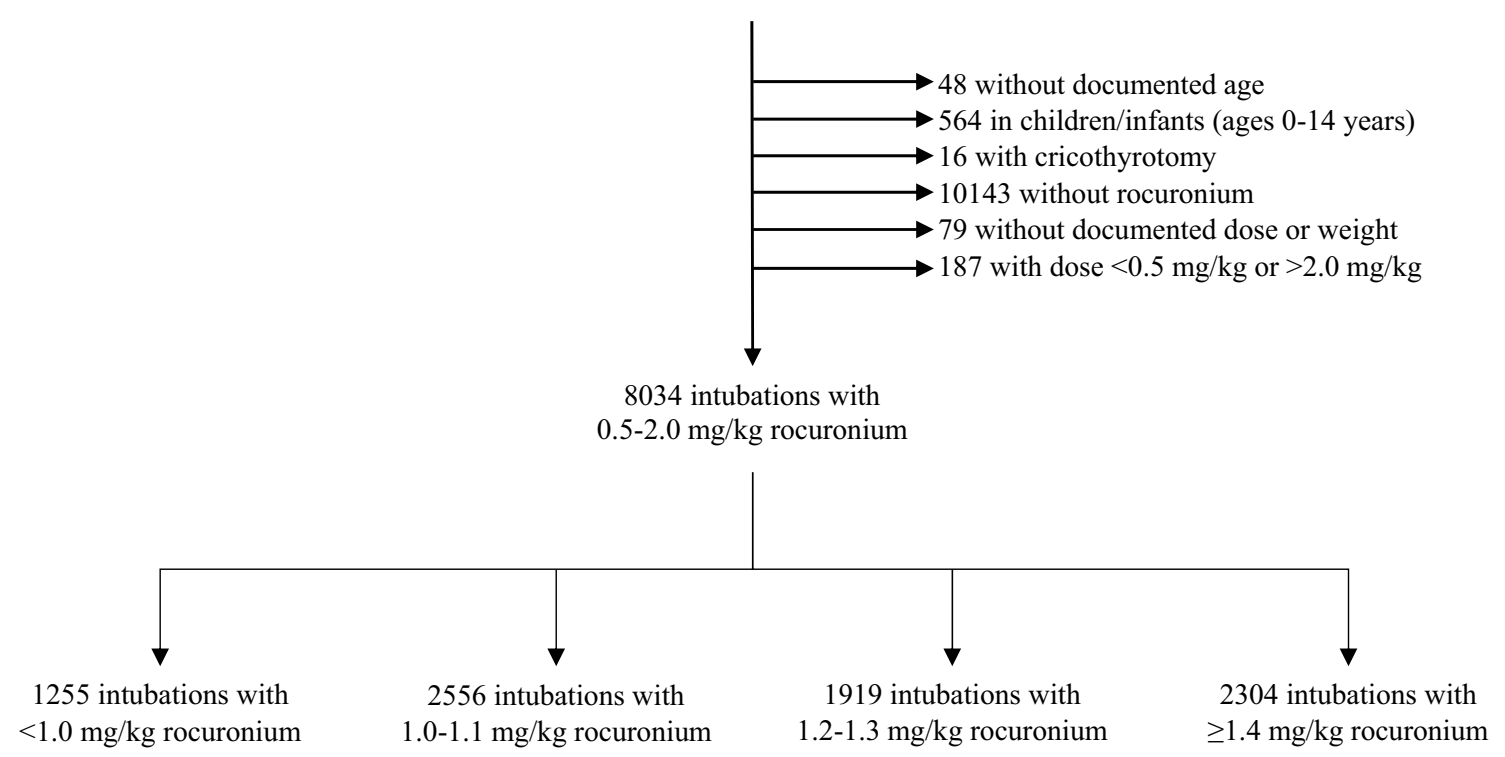

Fig. 1 Flow diagram of patient selection

\section{Objective}

To assess the relationship of escalating weight-based dosing for rocuronium on first-attempt intubation success and periintubation adverse events in adult ED patients.

\section{Methods}

\section{Data source and study population}

We analyzed data from the National Emergency Airway Registry (NEAR), an observational 25-center registry of ED intubations. The majority of EDs are affiliated with academic medical centers. Registry-wide recording compliance of $90 \%$ was required for data inclusion. Each participating site obtained prior approval from its local institutional review board. Intubating providers completed the standardized data collection instrument after each individual intubation by accessing a centralized electronic data management database (StudyTRAX, Macon, GA). Study investigators reviewed all data using quality assurance algorithms to identify and correct data entry errors. We recorded all data in accordance with the Strengthening the Reporting of Observational Studies in Epidemiology states (STROBE) [7].

\section{Selection of participants}

All patients $>14$ years of age who underwent rapid sequence intubation with rocuronium between 1 January 2016 and 31 December 2018 were candidates for inclusion. We excluded patients with no documented age, dose, or weight. We also excluded patients who received $<0.5$ or $>2.0 \mathrm{mg} / \mathrm{kg}$ of rocuronium as these may have represented data entry errors (Fig. 1).

\section{Study variables and outcomes}

We selected encounter variables $a$ priori based on their historically known associations with intubation outcomes. This follows the guidance outlined by Lederer et al. on controlling for controlling of confounding in casual inference studies [8]. Variables included were patient demographics, indication for intubation, pre-intubation hemodynamics, difficult airway characteristics, preoxygenation modalities, pretreatment medications, induction and neuromuscular bocking agents used along with dosages, intubation position and device, intubator characteristics, best glottic view, first-pass intubation success or failure, peri-intubation adverse events, intubation confirmation method, peri-intubation vitals and disposition.

The primary outcome was first-attempt intubation success. NEAR defines an intubation attempt as a single effort to place an endotracheal tube in which the leading edge of 
the laryngoscope blade entered the oral cavity past the alveolar ridge [9].

Secondary outcomes included incidence of any adverse event. Adverse events included cardiac arrest, dental trauma, direct airway injury, bradydysrhythmias, epistaxis, esophageal intubation, hypotension (systolic blood pressure $<100 \mathrm{~mm} \mathrm{Hg}$ ), hypoxemia (oxygen saturation $<90 \%$ ), iatrogenic bleeding, laryngoscope failure, laryngospasm, lip laceration, main-stem intubation, pharyngeal laceration, pneumothorax, endotracheal tube cuff failure, or vomiting with aspiration. Other outcomes included best Cormack-Lehane view and lowest peri-intubation oxygen saturation [10].

\section{Statistical analysis}

We assessed the primary outcome stratified by differing doses of rocuronium, including: $<1.0,1.0-1.1,1.2-1.3$, and $\geq 1.4 \mathrm{mg} / \mathrm{kg}$. The decision to use these dosing groups was made in part on various historical dosing practices and in part to optimize a similar number of patients in each comparator group. During this process, we also constructed a restricted cubic spline to model the nonlinear relationship between dose and first-pass success using five quintile knots at $0.96,1.02,1.18,1.31$, and $1.43 \mathrm{mg} / \mathrm{kg}$ (Supplemental Figure 1). We made univariate comparisons among these four groups using Cochran-Armitage trend tests (for nominal variables) and Kruskal-Wallis tests (for non-normal continuous variables).

We extended these comparisons using multivariable logistic regression models to calculate adjusted odds ratios with $95 \%$ confidence intervals. These models were clustered by NEAR site and adjusted for sex, body habitus, indication (trauma versus medical patient), initial impression of airway difficulty, intubation position, laryngoscope type, sedative medications, and operator characteristics. We conducted diagnostic tests prior to modeling the data, to include screening for collinearity, assessing outliers, and testing for key assumptions, and found no evidence of violation of the assumptions. We also performed subgroup analyses stratified by device (direct vs. video laryngoscopy) and pre-intubation hemodynamics. We report univariate descriptive statistics and odds ratios (OR) from multivariable logistic regressions with cluster-adjusted 95\% confidence intervals (CI).

\section{Results}

Over the 3-year period, 19,071 encounters were recorded. Of those, 8,034 were rapid sequence intubations using rocuronium within the defined dosing range (Fig. 1). Among these,
45.7\% utilized direct laryngoscopy while $53.4 \%$ used video laryngoscopy.

Patients in the lower dose group were more likely to be classified as obese or morbidly obese and had higher mean total body weight, $103.8 \mathrm{~kg}$ in the $<1 \mathrm{mg} / \mathrm{kg}$ dose group to $67.3 \mathrm{~kg}$ in the $\geq 1.4 \mathrm{mg} / \mathrm{kg}$ dose group (Table 1 ). The higher dose groups were also more likely to undergo intubation for a traumatic indication and have facial trauma (23.6 and $12.2 \%$ in the $\geq 1.4 \mathrm{mg} / \mathrm{kg}$ dose group compared to $15.8 \%$ and $6.9 \%$ for the $1 \mathrm{mg} / \mathrm{kg}$ dose group). A greater proportion of patients, $45.3 \%$, in the $<1 \mathrm{mg} / \mathrm{kg}$ dose group had an initial impression of difficult airway compared to $24.3 \%$ in the $\geq 1.4 \mathrm{mg} / \mathrm{kg}$ dose group.

First attempt success across dosing ranges was $88.4 \%$ for the $<1.0 \mathrm{mg} / \mathrm{kg}, 88.1 \%$ for $1.0-1.1 \mathrm{mg} / \mathrm{kg}, 89.7 \%$ for $1.2-1.3 \mathrm{mg} / \mathrm{kg}$ and $92.2 \%$ for the $\geq 1.4 \mathrm{mg} / \mathrm{kg}$ dose groups (Table 2). When compared to the $1.0-1.1 \mathrm{mg} / \mathrm{kg}$ group, the adjusted odds of first-attempt success were highest in the $\geq 1.4 \mathrm{mg} / \mathrm{kg}$ group, 1.5 (95\% CI 1.1-2.0). The adjusted odds of the remaining dosing groups of $<1.0 \mathrm{mg} / \mathrm{kg}$ and $1.2-1.3 \mathrm{mg} / \mathrm{kg}$ were 1.1 (95\% CI $1.0-1.4)$ and $1.2(95 \% \mathrm{CI}$ 0.9-1.5), respectively (Figs. 2, 3). The rates of all peri-intubation adverse events and desaturation were similar between groups (Supplemental Table 1).

\section{Hypotensive vs. normo-/hypertensive}

Patients who were hypotensive ( $\mathrm{SBP}<100 \mathrm{mmHg}$ ) prior to intubation had higher first-attempt success $94.9 \%$ versus $88.6 \%$ when higher doses of rocuronium were used (Table 2, Fig. 2). Rates of peri-intubation adverse events and desaturation were similar between groups (Supplemental Table 3).

\section{Direct laryngoscopy (DL) vs. video laryngoscopy (VL)}

When direct laryngoscopy was used and when comparing to the standard dosing range of $1.0-1.1 \mathrm{mg} / \mathrm{kg}$, the adjusted odds of a first attempt success was significantly higher in $\geq 1.4 \mathrm{mg} / \mathrm{kg}$ group at 1.9 (95\% CI $1.3-2.7)$ relative to the other dosing ranges, OR 0.9 (95\% CI $0.7-1.2)$ for $<1.0 \mathrm{mg} /$ $\mathrm{kg}$ and OR 1.2 (95\% CI 0.9-1.7) for the $1.2-1.3 \mathrm{mg} / \mathrm{kg}$ group (Fig. 4). First-attempt success was similar across all dosing ranges with video laryngoscopy. The rates of all peri-intubation adverse events and desaturation were similar between groups (Supplemental Table 2).

\section{Discussion}

\section{Interpretation of findings}

We observed an association of overall higher first-attempt success with rocuronium doses of $1.4 \mathrm{mg} / \mathrm{kg}$ or more 
Table 1 Patient characteristics

\begin{tabular}{|c|c|c|c|c|c|c|}
\hline Variable & $\begin{array}{l}\text { Rocuronium, all } \\
\text { doses }(n=8034)\end{array}$ & $<1.0 \mathrm{mg} / \mathrm{kg}(n=1255)$ & $\begin{array}{l}1.0-1.1 \mathrm{mg} / \\
\mathrm{kg} \\
(n=2556)\end{array}$ & $\begin{array}{l}1.2-1.3 \mathrm{mg} / \\
\mathrm{kg} \\
(n=1919)\end{array}$ & $\geq 1.4 \mathrm{mg} / \mathrm{kg}(n=2304)$ & $p$ \\
\hline Mean age (SD), years & $54.0(19.4)$ & $55.6(17.9)$ & $54.7(18.8)$ & $53.5(19.5)$ & $52.6(20.6)$ & $<0.0001$ \\
\hline Sex (female), $\%$ & 35.7 & 35.3 & 34.9 & 32.9 & 39.1 & 0.0147 \\
\hline Received $100 \mathrm{mg}$ rocuronium, $\%$ & 60.2 & 43.5 & 45.7 & 69.5 & 77.6 & $<0.0001$ \\
\hline Mean weight (SD), kg & $80.6(22.4)$ & $103.8(31.1)$ & $83.9(18.8)$ & $77.0(14.0)$ & $67.3(13.1)$ & $<0.0001$ \\
\hline \multicolumn{7}{|l|}{ Body habitus, $\%$} \\
\hline Very thin & 4.2 & 1.9 & 3.4 & 3.7 & 6.7 & $<0.0001$ \\
\hline Thin & 16.2 & 7.6 & 12.8 & 15.1 & 25.5 & $<0.0001$ \\
\hline Normal & 46.3 & 27.5 & 42.7 & 53.6 & 54.6 & $<0.0001$ \\
\hline Obese & 28.0 & 44.1 & 36.3 & 25.4 & 12.1 & $<0.0001$ \\
\hline Morbidly obese & 5.1 & 18.4 & 4.4 & 2.1 & 1.1 & $<0.0001$ \\
\hline Starting oxygen saturation (SD), $\%$ & $97.3(7.2)$ & $96.7(7.0)$ & $97.4(7.3)$ & $97.4(7.0)$ & $97.3(7.5)$ & $<0.0001$ \\
\hline $\begin{array}{l}\text { Pre-intubation hypotension } \\
\quad(\text { SBP }<100), \%\end{array}$ & 16.3 & 17.5 & 16.3 & 16.5 & 15.5 & 0.1014 \\
\hline \multicolumn{7}{|l|}{ Indication, \% } \\
\hline Medical & 80.2 & 84.1 & 82.7 & 79.0 & 76.2 & $<0.0001$ \\
\hline Traumatic & 19.6 & 15.8 & 17.2 & 20.5 & 23.6 & $<0.0001$ \\
\hline $\begin{array}{l}\text { Initial impression of difficult } \\
\text { airway, } \%\end{array}$ & 30.6 & 45.3 & 31.0 & 28.1 & 24.3 & $<0.0001$ \\
\hline Reduced neck mobility, $\%$ & 25.9 & 23.2 & 24.4 & 27.0 & 28.3 & $<0.0001$ \\
\hline Median Mallampati score (IQR) & $2(1-3)$ & $3(2-3)$ & $2(1-3)$ & $2(1-3)$ & $2(1-3)$ & $<0.0001$ \\
\hline Reduced mouth opening, $\%$ & 15.0 & 17.8 & 15.0 & 15.0 & 13.5 & 0.0008 \\
\hline Airway obstruction, $\%$ & 3.0 & 3.4 & 2.9 & 3.0 & 2.9 & 0.5106 \\
\hline Facial trauma, $\%$ & 9.7 & 6.9 & 8.4 & 10.1 & 12.2 & $<0.0001$ \\
\hline Blood or vomit in airway, $\%$ & 22.7 & 21.7 & 22.3 & 24.1 & 22.4 & 0.3954 \\
\hline $\begin{array}{l}\text { Any difficult airway } \\
\text { characteristic, }{ }^{\mathrm{a}} \%\end{array}$ & 60.0 & 61.8 & 58.8 & 60.5 & 59.9 & 0.7362 \\
\hline \multicolumn{7}{|l|}{ Device, $\%$} \\
\hline Direct laryngoscope & 45.7 & 42.1 & 48.7 & 45.9 & 44.0 & 0.6747 \\
\hline Video laryngoscope & 53.4 & 56.7 & 50.8 & 53.0 & 54.9 & 0.5469 \\
\hline Other & 0.4 & 0.8 & 0.3 & 0.5 & 0.3 & 0.1550 \\
\hline \multicolumn{7}{|l|}{ Sedation agent, $\%$} \\
\hline Etomidate & 78.9 & 79.3 & 80.4 & 77.6 & 78.3 & 0.1094 \\
\hline Ketamine & 13.9 & 11.2 & 12.9 & 15.3 & 15.2 & 0.0002 \\
\hline Propofol & 2.4 & 3.2 & 2.7 & 2.2 & 2.0 & 0.0146 \\
\hline Midazolam & 0.8 & 1.1 & 0.7 & 0.8 & 0.7 & 0.2147 \\
\hline None & 4.0 & 5.3 & 3.2 & 4.1 & 3.9 & 0.3949 \\
\hline \multicolumn{7}{|l|}{ Intubator characteristics, $\%$} \\
\hline Emergency medicine PGY1 & 2.4 & 3.1 & 2.3 & 2.0 & 2.3 & 0.1427 \\
\hline Emergency medicine PGY2 & 12.0 & 12.6 & 12.0 & 13.1 & 10.8 & 0.1606 \\
\hline Emergency medicine PGY3 & 34.2 & 34.6 & 33.6 & 32.1 & 36.5 & 0.1925 \\
\hline Emergency medicine PGY4 & 39.2 & 36.7 & 39.7 & 39.3 & 39.9 & 0.1567 \\
\hline Emergency medicine fellow & 7.1 & 7.4 & 7.4 & 7.8 & 6.2 & 0.1467 \\
\hline $\begin{array}{l}\text { Emergency medicine attending } \\
\text { physician }\end{array}$ & 1.1 & 1.2 & 1.1 & 1.4 & 1.0 & 0.6647 \\
\hline Other (non-emergency medicine) & 3.9 & 4.4 & 3.8 & 4.0 & 3.5 & 0.2718 \\
\hline
\end{tabular}

${ }^{\text {a } D i f f i c u l t ~ a i r w a y ~ c h a r a c t e r i s t i c s ~ i n c l u d e ~ r e d u c e d ~ n e c k ~ m o b i l i t y, ~ M a l l a m p a t i ~ s c o r e ~}>1$, reduced mouth opening, airway obstruction, facial trauma, and blood or vomit in airway

$p$ values are for Cochran-Armitage trend test or Kruskal-Wallis test 
Table 2 First-attempt outcomes for overall sample and stratified by pre-intubation SBP and device

\begin{tabular}{|c|c|c|c|c|c|c|}
\hline Variable & $\begin{array}{l}\text { Rocuronium, all } \\
\text { doses }(n=8034)\end{array}$ & $\begin{array}{l}<1.0 \mathrm{mg} / \mathrm{kg} \\
(n=1255)\end{array}$ & $\begin{array}{l}1.0-1.1 \mathrm{mg} / \mathrm{kg} \\
(n=2556)\end{array}$ & $\begin{array}{l}1.2-1.3 \mathrm{mg} / \mathrm{kg} \\
(n=1919)\end{array}$ & $\begin{array}{l}\geq 1.4 \mathrm{mg} / \mathrm{kg} \\
(n=2304)\end{array}$ & $p$ \\
\hline \multicolumn{7}{|l|}{ Overall } \\
\hline First-pass intubation success, $\%$ & 89.7 & 88.4 & 88.1 & 89.7 & 92.2 & $<0.0001$ \\
\hline Any adverse event, $\%$ & 14.0 & 15.7 & 15.2 & 13.4 & 12.3 & 0.0007 \\
\hline Peri-intubation desaturation, $\%$ & 8.0 & 10.2 & 9.0 & 7.6 & 6.1 & $<0.0001$ \\
\hline \multicolumn{7}{|l|}{ Pre-intubation $\mathrm{SBP}<100$} \\
\hline First-pass intubation success, $\%$ & 89.8 & 88.6 & 86.1 & 89.9 & 94.9 & 0.0006 \\
\hline Any adverse event, $\%$ & 20.7 & 17.7 & 23.1 & 21.2 & 19.4 & 0.9276 \\
\hline Peri-intubation desaturation, $\%$ & 8.9 & 7.7 & 10.8 & 9.2 & 7.0 & 0.3937 \\
\hline \multicolumn{7}{|l|}{ Pre-intubation $\mathrm{SBP} \geq 100$} \\
\hline First-pass intubation success, $\%$ & 89.9 & 88.8 & 88.6 & 90.1 & 91.9 & 0.0004 \\
\hline Any adverse event, $\%$ & 12.9 & 16.2 & 13.8 & 12.0 & 11.0 & $<0.0001$ \\
\hline Peri-intubation desaturation, $\%$ & 8.2 & 11.4 & 9.1 & 7.6 & 6.1 & $<0.0001$ \\
\hline \multicolumn{7}{|l|}{ Direct laryngoscopy } \\
\hline First-pass intubation success, $\%$ & 87.6 & 83.0 & 85.6 & 88.2 & 92.0 & $<0.0001$ \\
\hline Any adverse event, $\%$ & 13.1 & 15.5 & 13.6 & 12.6 & 11.5 & 0.0216 \\
\hline Peri-intubation desaturation, $\%$ & 7.0 & 8.7 & 7.7 & 6.8 & 5.2 & 0.0020 \\
\hline \multicolumn{7}{|l|}{ Video laryngoscopy } \\
\hline First-pass intubation success, $\%$ & 91.6 & 92.3 & 90.5 & 91.3 & 92.4 & 0.3856 \\
\hline Any adverse event, $\%$ & 14.8 & 15.9 & 16.8 & 13.9 & 13.0 & 0.0115 \\
\hline Peri-intubation desaturation, $\%$ & 9.0 & 11.5 & 10.4 & 8.1 & 6.8 & $<0.0001$ \\
\hline
\end{tabular}

$p$ values are for Cochran-Armitage trend test

Fig. 2 First-attempt success among varying rocuronium dosing groups compared to $1.0-1.1 \mathrm{mg} / \mathrm{kg}$. Error bars represent cluster-adjusted $95 \%$ confidence intervals. Comparisons are statistically significant if the confidence interval does not cross 1 (dotted line)

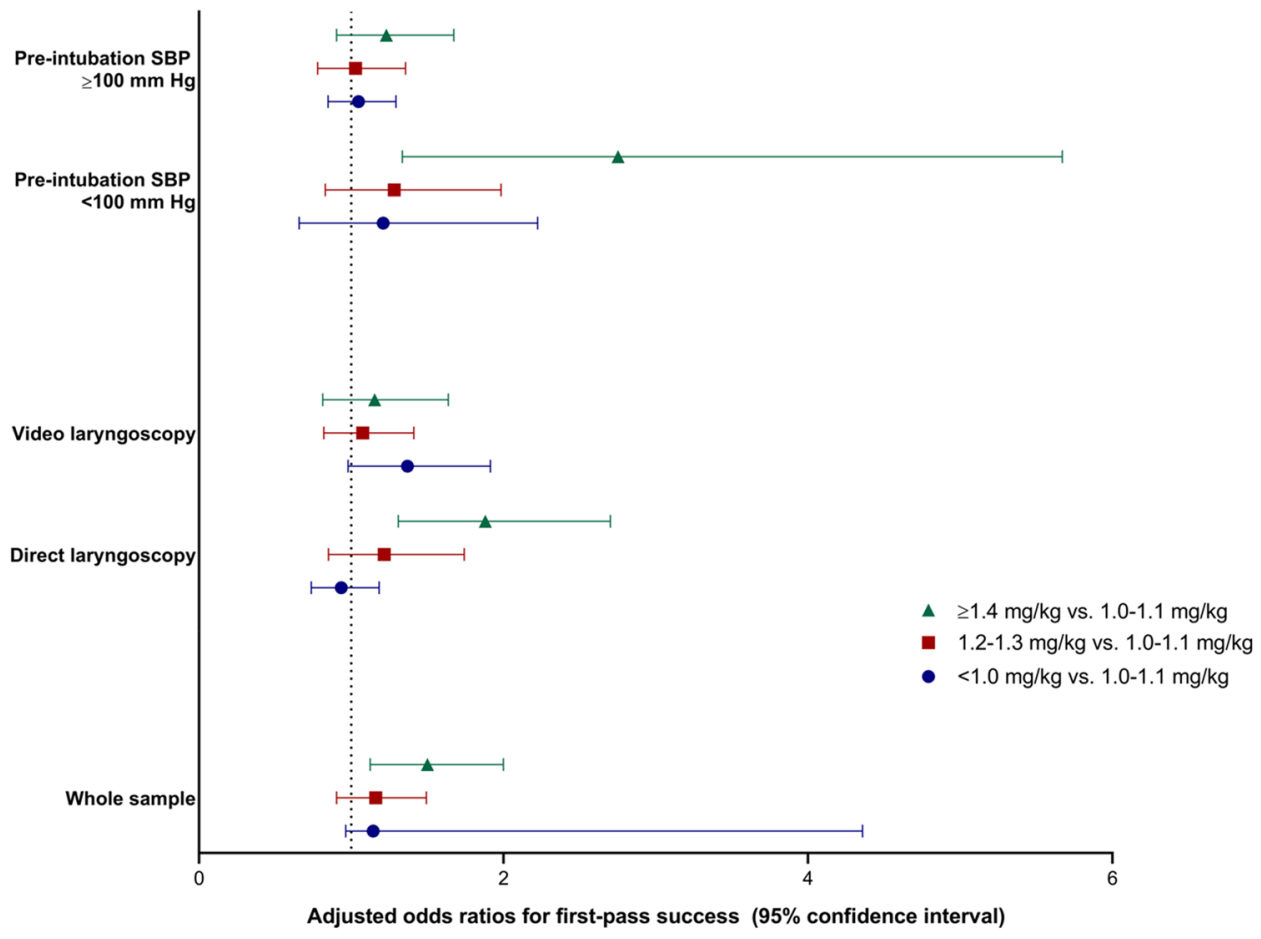


Fig. 3 First-attempt success among rocuronium doses. Error bars represent $95 \%$ confidence intervals

Fig. 4 First-attempt success among rocuronium doses, stratified by device. Error bars represent $95 \%$ confidence intervals
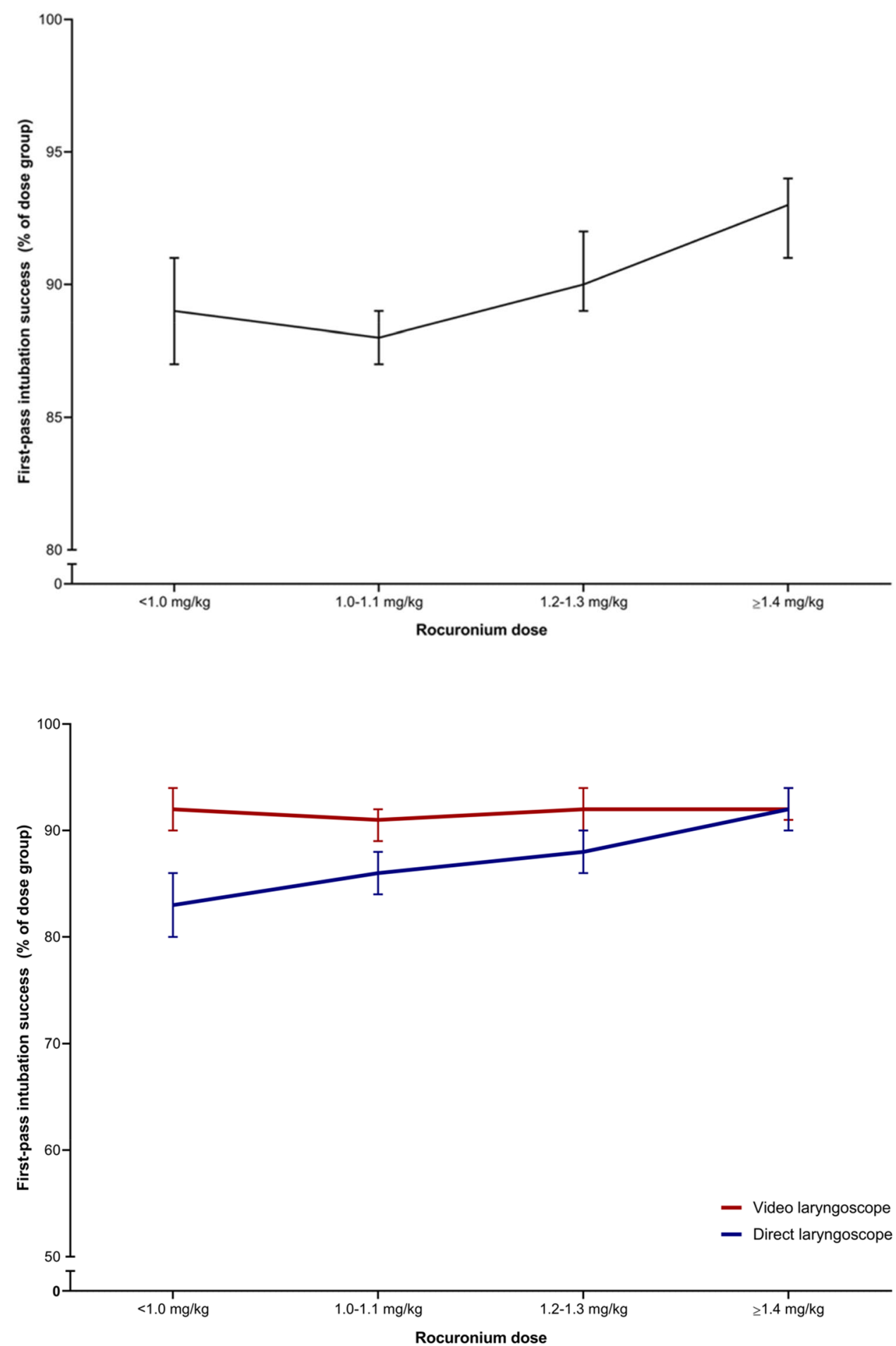

compared with lower dosing among rapid sequence intubations in the ED. An even higher effect estimate of first pass success was noted with direct laryngoscopy as there appeared to be a near-linear increase in intubation success with escalating doses of rocuronium ranging from $83 \%$ $(<1.0 \mathrm{mg} / \mathrm{kg}$ ) to $92 \%$ (at or above $1.4 \mathrm{mg} / \mathrm{kg}$ ). Intubations utilizing video laryngoscopy, however, had high rates of first pass success (90-92\%) across all doses of rocuronium. We believe this discrepancy is likely related to improved glottic exposure offered by VL compared with DL as several studies have shown that VL facilitates better glottic visualizations, reduced esophageal intubations, and higher rates of first pass success [11-16]. Presumably, patients who received a lower weight-based dose of rocuronium either had slower onset 
or incomplete paralysis making direct laryngoscopy more challenging while having minimal impact on VL.

Our study additionally suggests that utilizing higher dose rocuronium in patients exhibiting pre-intubation hypotension is associated with improved intubation success. As previously reported, pre-intubation hemodynamic instability is associated with worse outcomes [17]. As decreases in cardiac output affect rocuronium pharmacokinetics, hypotensive patients likely have reduced drug delivery and delayed onset or incomplete neuromuscular blockade at the time laryngoscopy is attempted [18]. Our observation of higher rates of first attempt success associated with higher doses of rocuronium may reflect a counterbalancing of reduced drug delivery with administration of more drug.

Based on our observation that heavier and obese body habitus patients were more likely to received lower weightbased doses of rocuronium suggests that EM providers are either bound by institutional limits for maximum rocuronium administration or providers are reflexively giving a standard dose (i.e., $100 \mathrm{mg}$ of rocuronium) irrespective of the patient's actual body weight. In our dataset, the mean weight of patients in the $<1.0 \mathrm{mg} / \mathrm{kg}$ group was $103.8 \mathrm{~kg}$ compared to $67.3 \mathrm{~kg}$ in the $\geq 1.4 \mathrm{mg} / \mathrm{kg}$ group; both equate to approximately $100 \mathrm{mg}$ of rocuronium administered. This is likely a consequence of it being an easy number to remember and also happens to be the standard size of the vials [19]. While standard doses offer simplicity, this study highlights the importance of accurate weight-based dosing to avoid the undesirable combination of a morbidly obese difficult airway who is inadvertently underdosed and therefore only partially relaxed during laryngoscopy. This benefit should be appropriately weighed against the risk of making errors while attempting bedside calculations during high-acuity and stressful situations.

\section{Comparison to previous studies}

In emergency medicine, the standard rapid sequence intubation dose for rocuronium is $1.0-1.2 \mathrm{mg} / \mathrm{kg}$ [20, 21]. In contrast, in the operating room a dosing range of $0.45-0.9 \mathrm{mg} /$ $\mathrm{kg}$ is advocated [22]. This practice variation likely reflects differences in the setting and goals of airway management as higher doses may result in faster onset at the expense of prolonged paralysis [23, 24]. Anesthesia providers more often intubate in a controlled setting and prefer a shorter duration of neuromuscular blockade to facilitate operating room turnover, whereas emergency medicine providers prioritize efficient and optimal intubating conditions with less concern about titrating to a short anesthetic time.

The majority of rocuronium dosing research to date comes from the anesthesia literature and is the basis for the manufacturer's package insert guidance that for rapid sequence intubation, " 0.6 to $1.2 \mathrm{mg} / \mathrm{kg}$ will provide excellent or good intubating conditions in most patients in less than 2 min". TEVA pharmaceutical cites 11 studies where the doses ranged $0.6-0.85 \mathrm{mg} / \mathrm{kg}$ and only two studies that evaluated larger dose rocuronium ranging from $0.9-1.2 \mathrm{mg} / \mathrm{kg}$ [19]. This was acknowledged as a limitation for comparisons to succinylcholine intubations in a recent Cochrane review [3].

Despite limited investigations into higher doses of rocuronium typically used during emergency airway management, several studies point to improved outcomes with increasing doses. One double-blind comparison of elective surgical cases found that $0.9 \mathrm{mg} / \mathrm{kg}$ of rocuronium or $1.5 \mathrm{mg} /$ $\mathrm{kg}$ succinylcholine provided similar intubating conditions at $1 \mathrm{~min}$ and found that these doses were superior to $0.7 \mathrm{mg} / \mathrm{kg}$ of rocuronium [6]. Similarly, a study examining the effectiveness of neuromuscular blockade at varying rocuronium dosing found that $100 \%$ blockade occurred at $1.0 \mathrm{~min}$ for $0.9 \mathrm{mg} / \mathrm{kg}$ and $1.2 \mathrm{mg} / \mathrm{kg}$ but $1.3 \mathrm{~min}$ for $0.6 \mathrm{mg} / \mathrm{kg}$ [23]. An earlier randomized trial of operating room patients given varying doses of rocuronium ranging from $0.4 \mathrm{mg} / \mathrm{kg}$ to $2.0 \mathrm{mg} / \mathrm{kg}$ found that large doses of rocuronium $(2.0 \mathrm{mg} / \mathrm{kg})$ were necessary to obtain a greater than $90 \%$ probability of achieving ideal conditions for rapid sequence intubation [5]. They acknowledged this higher dose may be more appropriate for traumatic indications as the prolonged paralysis would not be ideal for typical elective surgery cases.

More recently, April et al. compared patient outcomes with succinylcholine versus rocuronium but only dichotomized rocuronium doses to $\geq 1.2$ or $<1.2 \mathrm{mg} / \mathrm{kg}$. They reported a better first attempt intubation success with higher rocuronium dosing among patients without difficult airway characteristics [2]. Our study expanded upon that analysis as we observed an association of overall higher first-attempt success with rocuronium doses of $1.4 \mathrm{mg} / \mathrm{kg}$ or more compared with lower dosing strategies. As repeated attempts of endotracheal intubation are associated with increased adverse events, we offer modest evidence to support utilizing larger doses of rocuronium for ED rapid sequence intubation [25].

\section{Strengths and limitations}

While our study is strengthened by inclusion of over eight thousand ED intubations from a multicenter dataset, it also comes with several limitations. Our self-reported data collection is susceptible to recall bias. As an attempt to reduce this, we required participating centers to maintain $>90 \%$ compliance with reporting and to complete the research surveys as soon as possible.

This analysis comprised an analysis of observational data. Consequently, we cannot determine causation between varying dosing groups and outcomes. In our data collection and subsequently in our multivariate regression analysis, we 
attempted to capture and include as many of these potentially confounding variables to account for their influence on outcomes. However, we cannot control for unmeasured confounders. Related to this and as stated previously, in the lower dosing group patients were more obese and more likely to have the initial impression of a difficult airway and generally these patients are inherently higher risk for poorer outcomes. While these variables were included into our multi-variate analysis, additional unmeasured characteristics of these patients could potentially contribute to the observed differences in first-attempt intubation success.

Improved first attempt success is best thought of as a process outcome. While there is an association between firstpass success and decreased in peri-intubation adverse events we did not observe an increase in adverse events across our dosing groups $[17,26]$. This may reflect underreporting. In addition, we are unable to make a causal statement about increased rocuronium dosing and patient morbidity or mortality.

While our study assesses the association between rocuronium dose and first pass success, our primary outcome may be impacted by unmeasured confounders such as time to laryngoscopy following drug administration. While not recorded in our registry, we have no reason to believe differences in time to first laryngoscopy would be unevenly distributed across dosing regimens. In fact, higher dosing may precipitate more rapid onset of neuromuscular blockade and provide better intubating conditions for "early lookers". Nevertheless, this and other provider level variations remain potential confounders.

Another potential limitation of our study is that our dosing thresholds were largely determined based upon sample size convenience and historical norms. While several of the group's cutoffs follow typical dosing regiments (i.e., $<1.0$ and $>1.0 \mathrm{mg} / \mathrm{kg}$ ), other cutoffs are more arbitrary. Should different cutoffs been selected, it is possible different associations could have been observed although it is very likely $\geq 1.4 \mathrm{mg} / \mathrm{kg}$ would still have shown a larger effect estimate for first pass success.

\section{Clinical and research implications}

For practitioners, our observations highlight the importance of calculating accurate weight-based rapid sequence intubation dosing patients with greater BMIs. For researchers, our observations offer guidance for further prospective study on the possible benefit of higher dose rocuronium for rapid sequence intubation with direct laryngoscopy and in patients with hypotension or shock.

\section{Conclusions}

In this large observational series, we observed an association of higher first attempt success with rocuronium dosed $\geq 1.4 \mathrm{mg} / \mathrm{kg}$ and higher among all ED intubations, particularly when direct laryngoscopy was used and among patients with pre-intubation hypotension, without an increase in adverse events.

Supplementary Information The online version contains supplementary material available at https://doi.org/10.1007/s43678-021-00119-6.

Author contributions NL, MF, and $\mathrm{CB}$ conceived of the study. MF, $\mathrm{MA}$, and CB supervised the study. AA provided statistical advice and analyzed the data. NL drafted the article, and all authors contributed substantially to its revision. RW is a senior NEAR investigator, founded the registry and contributed to manuscript development.

Funding NL reports no conflict of interest.

\section{Declarations}

Conflict of interest None of the authors have significant conflicts of interest to disclose.

\section{References}

1. Walls RM, Brown CA, Bair AE, Pallin DJ. Emergency airway management: a multi-center report of 8937 emergency department intubations. J Emerg Med. 2011;41(4):347-54.

2. April MD, Arana A, Pallin DJ, Schauer SG, Fantegrossi A, Fernandez J, et al. Emergency department intubation success with succinylcholine versus rocuronium: a national emergency airway registry study. Ann Emerg Med. 2018;72(6):645-53.

3. Tran DT, Newton EK, Mount VA, Lee JS, Wells GA, Perry JJ. Rocuronium versus succinylcholine for rapid sequence induction intubation. Cochrane Database Syst Rev. 2015. https://doi.org/10. 1002/14651858.CD002788.pub3/abstract.

4. Guihard B, Chollet-Xémard C, Lakhnati P, Vivien B, Broche C, Savary D, et al. Effect of rocuronium vs succinylcholine on endotracheal intubation success rate among patients undergoing out-of-hospital rapid sequence intubation: a randomized clinical trial. JAMA. 2019;322(23):2303-12.

5. Heier T, Caldwell JE. Rapid tracheal intubation with largedose rocuronium: a probability-based approach. Anesth Analg. 2000;90(1): 175

6. Weiss JH, Gratz I, Goldberg ME, Afshar M, Insinga F, Larijani G. Double-blind comparison of two doses of rocuronium and succinylcholine for rapid-sequence intubation. J Clin Anesth. 1997;9(5):379-82.

7. von Elm E, Altman DG, Egger M, Pocock SJ, Gøtzsche PC, Vandenbroucke JP, et al. The strengthening the reporting of observational studies in epidemiology (STROBE) statement: guidelines for reporting observational studies. PLoS Med. 2007;4(10):e296.

8. Lederer DJ, Bell SC, Branson RD, Chalmers JD, Marshall R, Maslove DM, et al. Control of confounding and reporting of results in causal inference studies. Guidance for authors from editors of respiratory, sleep, and critical care journals. Ann Am Thorac Soc. 2019;16(1):22-8. 
9. Brown CA, Bair AE, Pallin DJ, Walls RM. Techniques, success, and adverse events of emergency department adult intubations. Ann Emerg Med. 2015;65(4):363-70.

10. Cormack RS, Lehane J. Difficult tracheal intubation in obstetrics. Anaesthesia. 1984;39(11):1105-11.

11. Sakles JC, Javedani PP, Chase E, Garst-Orozco J, Guillen-Rodriguez JM, Stolz U. The use of a video laryngoscope by emergency medicine residents is associated with a reduction in esophageal intubations in the emergency department. Acad Emerg Med. 2015;22(6):700-7.

12. Jiang J, Kang N, Li B, Wu A-S, Xue F-S. Comparison of adverse events between video and direct laryngoscopes for tracheal intubations in emergency department and ICU patients-a systematic review and meta-analysis. Scand J Trauma Resusc Emerg Med. 2020;28(1):10.

13. Jiang J, Ma D, Li B, Yue Y, Xue F. Video laryngoscopy does not improve the intubation outcomes in emergency and critical patients-a systematic review and meta-analysis of randomized controlled trials. Crit Care. 2017;21(1):288.

14. Brown CA, Kaji AH, Fantegrossi A, Carlson JN, April MD, Kilgo $\mathrm{RW}$, et al. Video laryngoscopy compared to augmented direct laryngoscopy in adult emergency department tracheal intubations: a national emergency airway registry (NEAR) study. Acad Emerg Med. 2020;27(2):100-8.

15. Bhattacharjee S, Maitra S, Baidya DK. A comparison between video laryngoscopy and direct laryngoscopy for endotracheal intubation in the emergency department: a meta-analysis of randomized controlled trials. J Clin Anesth. 2018;47:21-6.

16. Brown CA, Bair AE, Pallin DJ, Laurin EG, Walls RM. National Emergency Airway Registry (NEAR) Investigators. Improved glottic exposure with the Video Macintosh Laryngoscope in adult emergency department tracheal intubations. Ann Emerg Med. 2010;56(2):83-8.

17. Schwartz DE, Matthay MA, Cohen NH. Death and other complications of emergency airway management in critically ill adults. A prospective investigation of 297 tracheal intubations. Anesthesiology. 1995;82(2):367-76.
18. Kuipers JA, Boer F, Olofsen E, Bovill JG, Burm AGL. Recirculatory pharmacokinetics and pharmacodynamics of rocuronium in patientsthe influence of cardiac output. Anesthesiology. 2001;94(1):47-55.

19. TEVA Pharmaceutical Ind. Ltd. Rocuronium Bromide Injection, Package Insert [Internet]. Jerusalem, Israel: FDA Drug Information. https://www.accessdata.fda.gov/drugsatfda_docs/label/2008/ 078717s000lbl.pdf

20. Meckler, Garth D, Stapczynski, J. Stephan, Cline, David M, Tintinalli, Judith E, and Ma, O. John. Tintinalli's emergency medicine: a comprehensive study guide. 8th edn. New York: McGrawHill; 2015.

21. Brown CA, Sakles JC, Mick NW. The walls manual of emergency airway management. Philadelphia: Lippincott Williams \& Wilkins; 2017. p. 895

22. Butterworth IV JF, Mackey DC, Wasnick JD. Neuromuscular Blocking Agents. In: Morgan \& Mikhail's Clinical Anesthesiology [Internet]. 6th edn. New York: McGraw-Hill; 2018 (cited 6 Aug 2020). accessmedicine.mhmedical.com/content. aspx?aid $=1161426824$

23. Schultz P, Ibsen M, Østergaard D, Skovgaard LT. Onset and duration of action of rocuronium-from tracheal intubation, through intense block to complete recovery. Acta Anaesthesiol Scand. 2001;45(5):612-7.

24. Kirkegaard-Nielsen H, Caldwell J, Berry P. Rapid tracheal intubation with rocuronium: a probability approach to determining dose. Anesthesiology. 1999;91(1):131-6.

25. Hasegawa K, Shigemitsu K, Hagiwara Y, Chiba T, Watase H, Brown $\mathrm{CA}$, et al. Association between repeated intubation attempts and adverse events in emergency departments: an analysis of a multicenter prospective observational study. Ann Emerg Med. 2012;60(6):749-754.e2.

26. Sakles JC, Chiu S, Mosier J, Walker C, Stolz U. The importance of first pass success when performing orotracheal intubation in the emergency department. Acad Emerg Med. 2013;20(1):71-8.

\section{Authors and Affiliations}

\section{Nicholas M. Levin ${ }^{1}$ (D) Megan L. Fix ${ }^{1} \cdot$ Michael D. April ${ }^{2}$ Allyson A. Arana ${ }^{3} \cdot$ Calvin A. Brown $\mathrm{III}^{4}$ - on behalf of the NEAR Investigators}

1 Division of Emergency Medicine, University of Utah School of Medicine, Salt Lake City, Utah, USA

2 Department of Military and Emergency Medicine, Uniformed Services University of the Health Sciences, Bethesda, MD, USA
3 The United Stated Army Institute of Surgical Research, San Antonio, TX, USA

4 Department of Emergency Medicine, Brigham and Women's Hospital, Harvard Medical School, Boston, MA, USA 